\title{
Análise da produção científica mediante a interdisciplinaridade entre a ciência da informação e a administração nos ambientes organizacionais
}

\author{
Beatriz Rosa Pinheiro dos Santos \\ Universidade Estadual Paulista, Faculdade de Filosofia e Ciências, Marília, SP, Brasil \\ beatriz.pinheiro@marilia.unesp.br \\ Camila de Biaggi \\ Universidade Estadual Paulista, Faculdade de Filosofia e Ciências, Marília, SP, Brasil \\ camila biaggi@hotmail.com
}

leda Pelógia Martins Damian

Universidade de São Paulo, Faculdade de Filosofia, Ciências e Letras de Ribeirão Preto, Ribeirão

Preto, SP, Brasil

ieda.martins@bol.com.br

ARTIGOS

DE REVISÃO

DOI: https://doi.org/10.26512/rici.v12.n1.2019.19115

Recebido/Recibido/Received: 2018-04-17

Aceitado/Aceptado/Accepted: 2018-11-14

Cassia Regina Bassan de Moraes

Faculdade de Tecnologia de Garça, Garça, SP, Brasil

crbassan@gmail.com

Resumo: O texto é uma revisão de literatura baseada em uma análise cientométrica sobre a interdisciplinaridade entre os campos científicos da Ciência da Informação e da Administração e a importância que o contexto revela para a atual sociedade da informação e do conhecimento. Considerada um campo interdisciplinar, a Ciência da Informação se apropria de alguns paradigmas e universos da administração, e esta última também utiliza metodologias e resultados de pesquisas da Ciência da Informação para seu próprio enriquecimento. Dessa maneira, o objetivo é avaliar o volume de produção científica que envolve a ligação entre a Ciência da Informação e Administração entre os anos de 2007 a 2017. Para isso, foi realizada uma pesquisa exploratória, de natureza qualitativa, utilizando a técnica de análise cientométrica. Os resultados demonstraram que praticamente todos os autores das pesquisas recuperadas que envolvem a interdisciplinaridade entre a Ciência da Informação e a Administração também possuem formação interdisciplinar entre as áreas. Por fim, conclui-se que esse campo possui potencialidade para se tornar um tipo de ciência administrativa, todavia, como se torna abusivo generalizar a área toda como uma possível ciência da administração, presume-se que alguns eixos da Ciência da Informação buscam apoiar o campo da Administração.

Palavras-chave: Administração. Ciência da informação. Cientometria. interdisciplinaridade. produção científica. 


\title{
Analysis of scientific production through the interdisciplinarity between the Information Science and the Administration in the organizational environments
}

\begin{abstract}
The text is a literature review based on a scientometric analysis on the interdisciplinarity between the scientific fields of Information Science and Administration and the importance that the context reveals for the current society of information and knowledge. Considered an interdisciplinary field, Information Science appropriates some paradigms and universes of the administration, and the latter also uses methodologies and results of Information Science researches for its own enrichment. In this way, the objective is to evaluate the volume of scientific production that involves the connection between Information Science and Administration between the years 2007 to 2017. For this, an exploratory research, of a qualitative nature, was carried out using the scientometric analysis technique - The results showed that practically all authors of the retrieved researches that involve the interdisciplinarity between Information Science and Administration also have interdisciplinary training between the areas. Finally, it is concluded that this field has the potential to become a kind of administrative science, however, since it is abusive to generalize the whole area as a possible management science, it is presumed that some axes of Information Science seek to support the field of Administration.
\end{abstract}

Keywords: Administration. Information science. interdisciplinarity. scientific production. Scientometrics.

\section{Análisis de la producción científica por la interdisciplinariedad entre la ciencia de la información y la administración en los ambientes organizacionales}

Resumen: El texto es una revisión de literatura basada en un análisis cientométrico sobre la interdisciplinaridad entre los campos científicos de la Ciencia de la Información y de la Administración y la importancia que el contexto revela para la actual sociedad de la información y del conocimiento. Considerada un campo interdisciplinario, la Ciencia de la Información se apropia de algunos paradigmas y universos de la administración, y esta última también utiliza metodologías y resultados de investigaciones de la Ciencia de la Información para su propio enriquecimiento. De esta manera, el objetivo es evaluar el volumen de producción científica que involucra el vínculo entre la Ciencia de la Información y Administración entre los años de 2007 a 2017. Para ello, se realizó una investigación exploratoria, de naturaleza cualitativa, utilizando la técnica de análisis cientométrico. Los resultados demostraron que prácticamente todos los autores de las investigaciones recuperadas que involucran la interdisciplinaridad entre la Ciencia de la Información y la Administración también poseen formación interdisciplinaria entre las áreas. Por último, se concluye que ese campo tiene potencial para convertirse en un tipo de ciencia administrativa, sin embargo, como se hace abusivo generalizar el área toda como una posible ciencia de la administración, se presume que algunos ejes de la Ciencia de la Información buscan apoyar el campo de la ciencia la administración.

Palabras clave: Administración. Ciencia de la Información. Cienciometria. interdisciplinaridad. producción científica.

\section{Introdução}

Este artigo parte do pressuposto de que os processos de gestão da informação e documental, oriundos do campo da Ciência da Informação (Cl) são cada vez mais utilizados pelas organizações, que estão dispostas a se desenvolverem e se adaptarem ao contexto da sociedade da informação e do conhecimento, onde a informação, em suas variadas formas (formal, informal, registrada ou não registrada), passou a ser considerada um recurso de 
extremo valor às organizações. Nesse sentido, presume-se que diante da inserção dos processos da Ciência da Informação nas organizações, esta ciência pode ser considerada uma ciência administrativa, visto que está atrelada ao campo da Administração por muitos aspectos.

Em uma definição clássica, Borko (1968) conceitua a Ciência da Informação como uma área que estuda o comportamento da informação, as propriedades dos fluxos de informação, e maneiras de gerenciá-la para otimizar sua acessibilidade e uso em qualquer contexto.

Para Ponjuán Dante (2007), a gestão da informação deve ser considerada um processo no qual se utilizam recursos econômicos, físicos, humanos e materiais para processamento, acesso e uso facilitado da informação nos ambientes organizacionais. Em consonância, a autora define gestão documental como um processo administrativo que busca analisar e controlar a informação registrada e que está estritamente relacionada ao planejamento estratégico de uma organização, envolvendo o conjunto de missão, visão e valores.

A administração é uma prática social antiga, porém, vista há pouco tempo como um campo científico de fato. De maneira geral, essa prática social está baseada em um conjunto de processos que visam planejar e controlar os recursos de uma empresa, em busca do sucesso nas práticas organizacionais, com o objetivo de buscar a eficiência diária e a eficácia futura da organização (SANTOS, 2017).

Mediante esses conceitos, ficam evidentes as características em comuns entre a Ciência da Informação e a Administração e a relevância de uma para outra, enquanto campos que se enriquecem juntos. Até porque, de acordo com Araújo (2014), a Cl se configura como um campo científico em constante construção, tanto para a academia quanto para o âmbito social; e a Administração, segundo Santos (2017), se expressa como um saber interdisciplinar que se encontra em fase de consolidação para ser dada e reconhecida como uma ciência.

Diante dessas contextualizações, o objetivo desta pesquisa foi analisar o volume de produção científica que envolve o vínculo entre a $\mathrm{Cl}$ e a Administração entre os anos de 2007 a 2017. Para tanto, realizou-se uma pesquisa exploratória, de natureza qualitativa, utilizando a técnica de análise cientométrica.

Justifica-se esse estudo porque é importante para a $\mathrm{Cl}$ expandir horizontes no contexto prático e social, além do científico e acadêmico, por meio da sua aplicação como ciência administrativa, oferecendo aportes estratégicos às empresas.

\section{Metodologia}

O presente trabalho é caracterizado como uma pesquisa exploratória, de natureza quali-quantitativa. É definido como exploratória, porque se pretende reconhecer determinado 
objeto de pesquisa, através de reflexões, aprimoramento de ideias e aplicação de estudos mais aprofundados sobre o assunto, como afirma Gil (2012).

O estudo utiliza a cientometria para avaliar a produção científica sobre a interdisciplinaridade entre a $\mathrm{Cl}$ e a Administração no período de 2007 a 2017, em bases de dados nacionais e internacionais.

Segundo Callon, Courtial e Penan (1995), a cientometria é uma ciência que estuda as ciências e suas características de produção acadêmica, técnica e afins. Além disso, para os autores o termo cientometria também pode significar algo que visa medir a ciência.

Além da busca realizada no acervo da Biblioteca da Universidade Estadual Paulista Júlio de Mesquita Filho - Faculdade de Filosofia e Ciências de Marília, também foram analisadas duas bases de dados internacionais: Library and Information Science Abstracts (LISA) e Scopus, como também duas bases de dados de conteúdos nacionais: Base de Dados Referenciais de Artigos de Periódicos em Ciência da Informação (BRAPCI) e a coleção brasileira da SCIELO.

As palavras chave utilizadas nas bases de dados foram: 'ciência da informação e administração'; 'gestão da informação nas organizações' e 'gestão documental nas organizações'. As pesquisas selecionadas foram aquelas que utilizavam aportes da $\mathrm{Cl}$, como a gestão da informação e a gestão documental, no contexto de empresas, independentemente de serem públicas ou privadas. Ademais, verificou-se se os autores dessas pesquisas possuíam alguma formação interdisciplinar em $\mathrm{Cl}$, administração e áreas correlatas.

A cobertura da literatura foi construída por meio de uma revisão bibliográfica no portal de periódicos da CAPES e na base de dados BRAPCI, onde se pesquisou os conceitos e fundamentos da $\mathrm{Cl}$ como também da Gestão da Informação e da Gestão Documental, que são processos interdisciplinares, oriundos da $\mathrm{Cl}$, mas também utilizados pela Administração.

\section{Ciência da Informação: conceitos}

Os estudos indicam que o primeiro conceito de Ciência da Informação surgiu a partir das ideias de Taylor, em duas reuniões, com cerca de 60 profissionais, entre docentes e bibliotecários, realizadas no Georgia Institute of Technology, na National Science Foundation, no estado da Geórgia, nos Estados Unidos, em outubro de 1961 e em abril de 1962 (BARRETO, 2007). A partir da ideia de Taylor, de acordo com Borko (1968), a Cl é uma disciplina que concentra prioridades e o comportamento informacional, bem como os fluxos de informação e seus significados de processamento. Contém conhecimentos relacionados à origem, coleção, organização, armazenamento, recuperação, interpretação, transmissão, transformação e utilização da informação, o uso de códigos para a transmissão eficiente da mensagem e 
técnicas que são aplicadas tanto em computadores como em sistemas de programação.

Segundo Capurro e Hjorland (2007), conceituados estudiosos da área, a Ciência da Informação se refere a uma disciplina que cria uma estruturação de conhecimentos científico, tecnológico e de sistemas, relacionado à transferência de informação, com ênfase na aplicação de tecnologias modernas nestas áreas. De acordo com Saracevic (1996) a Cl possui três fortes características que são capazes de defini-la na atualidade e propor certa perspectiva da sua evolução: a primeira característica diz respeito a sua natureza interdisciplinar, a segunda expressa que a $\mathrm{Cl}$ está diretamente ligada aos aspectos tecnológicos e a terceira afirma que a área é responsável pela evolução da sociedade da informação, todavia, mais do que essas três importantes características que revelam o entorno da $\mathrm{Cl}$, o autor afirma que este campo científico desempenha uma função social e humana que ultrapassa a tecnologia, ou seja, vale inferir que a Ciência da Informação consegue enxergar que a tecnologia sozinha não possui valor e que é necessário trabalhar os aspectos humanos que a acompanham para que a mesma consiga alcançar bons resultados.

Com relação a esse contexto, Goffman (1970, apud SARACEVIC, 1996, p. 46) afirmou que

\begin{abstract}
"o objetivo da disciplina $\mathrm{Cl}$ deve ser o de estabelecer um enfoque científico homogêneo para estudo dos vários fenômenos que cercam a noção de informação, sejam eles encontrados nos processos biológicos, na existência humana ou nas máquinas... (A tarefa da $\mathrm{Cl}$ ) é o estudo das propriedades dos processos de comunicação que devem ser traduzidos no desenho de um sistema de informação apropriado para uma dada situação física".
\end{abstract}

A ideia do autor demonstra como a $\mathrm{Cl}$ se configura numa área que abarca vários aspectos relativos às práticas informacionais, independentemente do veículo (humano e/ou tecnológico). Concomitantemente, mediante a citação de Goffman, é possível dizer que de maneira geral, a $\mathrm{Cl}$ busca facilitar o processo comunicacional existente na vida das pessoas, por meio do estudo das propriedades da informação.

Para Bottle (2003), a Cl é considerada uma disciplina que investiga diretamente as características da informação e o processo de transferência e difusão das informações, levando-se em consideração os aspectos da coleta, avaliação, organização e disseminação da informação realizada pelos aparatos tecnológicos.

Shera e Cleveland (1977 apud BRAGA, 1995, p. 4) entendem Cl como uma

[...] ciência que investiga as propriedades e o comportamento da informação, as forças que governam o fluxo da informação e os meios de processamento da informação para acessibilidade e usabilidade ótimas. Os processos incluem a geração, disseminação, coleta, organização, armazenamento, recuperação, interpretação e uso da informação. A área é derivada de ou relacionada à matemática, lógica, linguística, psicologia, tecnologia computacional, pesquisa operacional, artes gráficas, 
comunicações, biblioteconomia, administração e algumas outras áreas.

A definição de Shera e Cleveland evidencia o caráter interdisciplinar da $\mathrm{Cl}$ e os processos que são executados no gerenciamento e cuidado com o objeto da área: informação. Dois importantes pesquisadores da área como Capurro e Hjorland $(2007$, p. 186) também abordam os processos de tratamento da informação como aspectos que definem o campo, portanto, para eles, a $\mathrm{Cl}$

Se ocupa com a geração, coleta, organização, interpretação, armazenamento, recuperação, disseminação, transformação e uso da informação, com ênfase particular, na aplicação de tecnologias modernas nestas áreas. Como uma disciplina, procura criar e estruturar um corpo de conhecimentos científico, tecnológico e de sistemas, relacionado à transferência de informação.

Por fim, mais do que abordar as etapas do gerenciamento e tratamento da informação, o renomado pesquisador Saracevic (1996, p. 47) contextualiza a Cl como um campo que se dedica a produção informacional humana também.

A Ciência da Informação é um campo dedicado às questões científicas e à prática profissional voltadas para os problemas da efetiva comunicação do conhecimento e de seus registros entre os seres humanos, no contexto social, institucional ou individual do uso e das necessidades da informação. No tratamento destas questões são consideradas de particular interesse as vantagens das modernas tecnologias informacionais.

Em essência, a Ciência da Informação investiga as propriedades e o comportamento da informação, o uso e a transmissão da informação, e o seu processamento, visando uma armazenagem e uma recuperação ideal, assim como um entendimento profundo da mensagem que é passada em um processo comunicacional, que se cria mediante informação e intervenção humana.

\subsection{Gestão da Informação e Gestão Documental}

Para um melhor entendimento sobre a $\mathrm{Cl}$, pode-se apontar que seu campo é também integrado pelas práticas de Gestão da Informação (GI) e Gestão Documental (GD).

Segundo Santos (2012), o documento pode ser definido como um tipo de suporte de fixação da escrita, desenho e som, que tem por objetivo preservar parte da memória humana ao longo do tempo. De acordo com Calderon et al (2004, p. 100), o documento arquivístico também é um ambiente de guarda de informações que "[...] em qualquer instituição pública ou privada, são de caráter contábil/financeira, pessoal e administrativa, que podem ser encontradas em diferentes espécies documentais". Com base nesta ideia, é possível dizer que a GD está ligada à informação que percorre o dia a dia das organizações e que exige do 
profissional seu total conhecimento das suas atividades diárias, visto que as informações contidas nos documentos a ser gerenciados são provenientes das atividades relativas à sua função.

Duranti (1994) destaca quatro características que definem o documento arquivístico: a imparcialidade, a autenticidade, a naturalidade e o inter-relacionamento. Para a autora, os documentos são imparciais porque são produzidos no âmbito das ações administrativas e só podem ser qualificados dentro das especificidades desta ação, não sendo possível atribuir valores externos a ele; são autênticos, pois são criados para suprir futuras necessidades informacionais diante das tomadas de decisão, num contexto funcional específico para o qual se configura como o instrumento jurídico ou administrativo válido; são naturais porque não surgem de forma mecânica ou programada, mas sim, são produzidos de acordo com as atividades exercidas por alguém e/ou pelas funções que demandam uma organização; e quanto à última característica, o inter-relacionamento justifica o fato de que os documentos de uma organização se relacionam, bem como o seu conteúdo, estabelecendo o vínculo de interdependência representado pela organicidade.

No âmbito atual da sociedade, em que a informação é produzida e recebida em grandes quantidades pelas organizações, se destaca a necessidade ainda mais acentuada de se realizar a GD, cuja relevância é evidenciada há muito mais tempo.

No Brasil, a GD é definida, de acordo com a Lei n. 8.159 de 8 de janeiro de 1991, em seu artigo 3 o como "o conjunto de procedimentos e operações técnicas referentes à sua produção, tramitação, uso, avaliação e arquivamento em fase corrente e intermediária, visando a sua eliminação ou recolhimento para guarda permanente".

Nisto, Bernardes e Delatorre (2008) conceituam a GD como um conjunto de normas técnicas referentes ao tratamento, uso e arquivamento efetivo dos documentos, onde são definidos seus prazos de guarda e destinação final. Nesta definição, os autores ainda reiteram que esta gestão é essencial também para o desenvolvimento dos sistemas de gestão da informação.

Indolfo (2007) e Conarq (2011) exprimem que a GD é um conjunto de operações e processos estacionados em meio ao ciclo de vida dos documentos probatórios, históricos e com valor informativo, não apenas capaz de gerenciar as atividades de uso e destinação final dos documentos, mas também e não menos importante a etapa de produção, considerada pelo autor o início de todo o processo da GD.

Esta ideia se assemelha à definição da UNESCO sobre GD, que segundo Heredia Herrera (1993) é definida como uma parte do processo administrativo relacionada à eficiência na produção, trâmite, uso e eliminação dos documentos em sua fase intermediária ou 
recolhimento aos arquivos históricos.

A eficácia do sistema resultará na obtenção de qualidade e quantidade [adequada] de documentos produzidos, evitando a acumulação irracional; simplificação de atividades, coordenação entre órgãos de produtores e arquivos, eliminação sistemática, informação atualizada; informação complementares, em última análise fluidez e eficácia (HEREDIA HERRERA, 1993, p. 178, tradução nossa).

Santos (2007) é mais específico e acredita que a GD é um fenômeno com funções arquivísticas que se preocupa com a produção, avaliação, aquisição, preservação, classificação, descrição, difusão, acesso e ciclo de vida dos documentos.

Em paralelo, a Gl fundamenta-se nos princípios da anterior Gestão dos Recursos Informacionais (GRI), considerada um processo que tinha como intuito gerenciar a informação de maneira estratégica e eficaz. De acordo com Barbosa e Paim (2003), já na década de 1970, a GRI era considerada um modelo de gestão que se encontrava em projeção com o campo científico da administração, da ciência da computação e da ciência da informação, que, de certa maneira e até hoje, são ciências pilares da informação, que lidam diariamente com o tratamento, armazenamento e utilização da mesma.

O escopo superficial da GRI e da GI é basicamente o mesmo, onde, de acordo com Alvarenga Neto (2008), o gerenciamento da informação é importante para dar respostas aos problemas informacionais das organizações, com o intuito de disponibilizar informação de qualidade no momento certo e para as pessoas certas.

Segundo Davenport (2001) e Beal (2008), a GI vai além do panorama tecnológico e do universo pautado pelos sistemas de informação, pois inclui aspectos voltados à cultura organizacional, que também é importante para a produção, tratamento e gerenciamento de informações. Ou seja, não basta apenas a inserção de sistemas tecnológicos de informação em um ambiente organizacional para dizer que há gestão da informação neste ambiente, já que a Gl trata também da informação empírica e informal.

Nessa mesma linha de raciocínio, Beal (2008) enfatiza que um dos aspectos mais ignorados da Gl está justamente na informação não estruturada, presente na forma verbal, nas notícias e no fluxo informacional informal diário das organizações. Por esse lado, deve-se dar importância a esse tipo de informação, que tem potencial para, futuramente, por meio do tratamento e da gestão, se tornar uma informação legitima, formal, estruturada e estratégica para uma organização.

Rascão (2006) aborda a GI como uma ferramenta e um processo que enxerga a informação como construção social, onde a linguagem, o pensamento, o diálogo e a comunidade devem ser os objetos de estudo, pois também são objetos de estudo da Ciência 
da Informação.

Em uma definição clássica, Ponjuán Dante (2007, p. 19, tradução nossa) pontua que a GI é

\begin{abstract}
o processo mediante o qual se obtém, se desenvolve ou se utilizam recursos básicos (econômicos, físicos, humanos, materiais) para o manejo da informação no âmbito e para a sociedade a qual serve. Tem como elemento básico a gestão do ciclo de vida desse recurso e ocorre em qualquer organização. É própria, também, de unidades especializadas que manejam esse recurso de forma intensiva, chamadas de unidades de informação. Esse processo de gestão da informação deve ser valorado sistematicamente em diferentes dimensões, e o domínio de suas essências permite sua aplicação em qualquer organização.
\end{abstract}

De acordo com Choo (2003), uma Gl efetiva faz com que as organizações: (i) se adaptem às mudanças do ambiente no momento adequado e de maneira eficaz; (ii) empenhem-se na aprendizagem constante, estando abertas ao ato de desprenderem de pressupostos, normas e crenças que perderam validade; (iii) mobilizem a experiência de seus funcionários para gerar inovação e criatividade; e (iv) focalizem seu conhecimento em ações racionais e decisivas.

Além disso, para Tarapanoff (2001), o objetivo central da Gl é potencializar os recursos informacionais e a informação em si e disponibilizá-los aos sujeitos organizacionais para contribuir com o crescimento e desenvolvimento das organizações, fazendo com que essas se adaptem da melhor maneira possível na atual sociedade.

Aqui cabe enfatizar que existem diversos campos científicos que possuem a informação como objeto central para auxílio na realização de seus objetivos, como a Ciência da Informação, Ciência da Computação, Ciência Contábil, Administração, Ciência da Psicologia, Ciência Pedagógica, entre outras (DE SORDI, 2008). Logo, evidencia-se que a GI é uma ferramenta que deve pontuar as mais distintas áreas do conhecimento, assim como em todas as organizações contemporâneas que lidam diariamente com informação em massa em seus contextos de trabalho.

Dado exposto, Valentim (2008) acredita que as organizações, independentemente da sua natureza, necessitam urgentemente compreender que possuem o poder de modificar a cultura do país, quanto ao acesso, gerenciamento e uso da informação e do conhecimento. A autora enfatiza que um país sem informação e conhecimento é um país sem desenvolvimento econômico e social, assim, analogicamente, uma organização que não valoriza a Gl no seu contexto organizacional também corre o risco de não desenvolver com qualidade os produtos e serviços ofertados à sociedade.

Enfim, de uma forma geral, a GI se refere às ações relacionadas à "obtenção da 
informação adequada, no formato correto, para a pessoa indicada, a um custo adequado, no tempo oportuno e em lugar apropriado para se tomar a decisão correta" (WOODMAN, 1985 apud PONJUÁN DANTE, 1998, p. 135).

Para isso, é necessária a aplicação da GD com técnicas de produção, tramitação, uso, avaliação e arquivamento de documentos em fase corrente e intermediária, visando a sua eliminação ou o seu recolhimento, desde a sua produção até o seu destino final, podendo ser recolhido para guarda permanente ou ser descartado (ARQUIVO NACIONAL, 2005).

\section{0 encontro entre a Ciência da Informação e a Administração}

Os fazeres administrativos utilizam informações que precisam ser gerenciadas e organizadas da melhor maneira possível, por isso, a GI e a GD são processos importantes e necessários para o desenvolvimento das atividades de toda e qualquer organização. 0 contexto organizacional e informacional requer atividades comuns que vão desde o planejamento estratégico até o controle operacional, assim como enfoques que dizem respeito à política, à economia, à cognição, à estratégia, ao gerenciamento e ao social. Autores como Borko (1968) e Saracevic (1996) explicam o encontro entre Cl e a ciência administrativa, tecendo considerações que se expõe na efetiva gestão dos recursos informacionais no ambiente organizacional.

Contudo, a Administração e a $\mathrm{Cl}$ se inter-relacionam pela sua efetividade na construção da comunicação humana, do conhecimento, dos registros do conhecimento, da informação, das necessidades de informação e dos usos da informação no contexto social, institucional, individual e tecnológico (SARACEVIC, 1996).

Essa interligação funcional vigora na prática e em atributos que, minuciosamente, definem os caminhos de intersecção dessas duas ciências. A interdisciplinaridade entre as duas áreas ocorre de maneira ampla e efetiva, gera valor informacional e produtivo para as organizações, sendo o elo que constitui matéria-prima para informar e administrar.

\section{Resultados e Discussões}

A tabela 1 apresenta a quantidade de materiais encontrados mediante a pesquisa dos termos: 'ciência da informação e administração'; 'gestão da informação nas organizações'; e 'gestão documental nas organizações' nas seguintes bases de dados: BRAPCI, SCIELO.

Cabe enfatizar que especificamente na LISA e SCOPUS foram pesquisados os seguintes descritores: 'information science and administration'; 'information management'; 'document management'; e 'record management'. Além do mais, a tabela 1 apresenta o resultado dos 
termos em inglês e português buscados nessas bases de dados, sem o uso das aspas.

É possível notar a expressiva quantidade de material que comprova a interdisciplinaridade entre a Ciência da Informação e a Administração, tanto em âmbito nacional como internacional, pois em média foram produzidos 42 pesquisas por ano nessas temáticas, mais precisamente quase 4 trabalhos por mês no Brasil. Enquanto que no contexto mundial foram produzidos aproximadamente 12.200 trabalhos por ano nos últimos dez anos, e uma média de um pouco mais de 1000 pesquisas por mês.

Tabela 1 - Produção Científica sobre a interdisciplinaridade entre a ciência da informação e a administração (descritores sem aspas)

\begin{tabular}{|c|c|c|c|c|c|}
\hline \multirow{2}{*}{$\begin{array}{c}\text { Termos pesquisados } \\
\text { em português }\end{array}$} & \multicolumn{2}{|c|}{$\begin{array}{l}\text { Base de dados/2007- } \\
2017\end{array}$} & \multirow{2}{*}{$\begin{array}{c}\text { Termos pesquisados } \\
\text { em inglês }\end{array}$} & \multicolumn{2}{|c|}{$\begin{array}{c}\text { Base de dados/2007- } \\
2017\end{array}$} \\
\hline & BRAPCI & SCIELO & & LISA & SCOPUS \\
\hline $\begin{array}{c}\text { ciência da } \\
\text { informação e } \\
\text { administração }\end{array}$ & 159 & 13 & $\begin{array}{l}\text { information science } \\
\text { and administration }\end{array}$ & 6.892 & 4.165 \\
\hline $\begin{array}{c}\text { gestão da informação } \\
\text { nas organizações }\end{array}$ & 164 & 52 & $\begin{array}{l}\text { information } \\
\text { management in } \\
\text { organizations }\end{array}$ & 15.458 & 61.377 \\
\hline $\begin{array}{l}\text { gestão documental } \\
\text { nas organizações }\end{array}$ & 21 & 11 & $\begin{array}{c}\text { document } \\
\text { management in } \\
\text { organizations }\end{array}$ & 9.403 & 7.676 \\
\hline --------------------- & --------- & ---------- & $\begin{array}{l}\text { record management } \\
\text { in organizations }\end{array}$ & 5.506 & 11.256 \\
\hline Total & 344 & 76 & |------------------- & 37.259 & 84.474 \\
\hline
\end{tabular}

Fonte: Elaborada pelas autoras.

Isso de fato comprovaria a forte corrente interdisciplinar entre as áreas da Administração e da $\mathrm{Cl}$, todavia, há de se considerar que muitas dessas pesquisas não estão realmente restritas à gestão da informação e da documentação nos ambientes organizacionais, ou à união entre os campos da Administração e da $\mathrm{Cl}$.

Por isso, a Tabela 2 apresenta a busca dos mesmos descritores nas mesmas bases de dados anteriormente pesquisadas, utilizando aspas em cada termo, com o intuito de buscá-los de maneira exata e detalhada nos trabalhos. A pesquisa utilizando aspas nos descritores retornou em números menores, no entanto suficientes para se fazer a análise proposta pelo artigo.

Utilizando os dados da Tabela 2, será analisado o currículo dos autores, a fim de verificar se os mesmos fossem alguma formação interdisciplinar em Administração ou áreas afins, juntamente com a Ciência da Informação. Optou-se por analisar os trabalhos recuperados apenas nas bases de dados brasileiras, pela facilidade de acesso ao currículo 
lattes dos autores.

Tabela 2 - Produção Científica sobre a interdisciplinaridade entre a ciência da informação e a administração (descritores com aspas)

\begin{tabular}{|c|c|c|c|c|c|}
\hline \multirow{2}{*}{$\begin{array}{c}\text { Termos pesquisados } \\
\text { em português }\end{array}$} & \multicolumn{2}{|c|}{$\begin{array}{l}\text { Base de dados/ 2007- } \\
2017\end{array}$} & \multirow{2}{*}{$\begin{array}{c}\text { Termos pesquisados } \\
\text { em inglês }\end{array}$} & \multicolumn{2}{|c|}{ Base de dados/ 2007-2017 } \\
\hline & BRAPCI & SCIELO & & LISA & SCOPUS \\
\hline $\begin{array}{l}\text { "ciência da } \\
\text { informação e } \\
\text { administração" }\end{array}$ & 0 & 6 & $\begin{array}{l}\text { "information science } \\
\text { and administration" }\end{array}$ & 3.928 & 517 \\
\hline $\begin{array}{l}\text { "gestão da } \\
\text { informação nas } \\
\text { organizações" }\end{array}$ & 0 & 0 & $\begin{array}{l}\text { "information } \\
\text { management in } \\
\text { organizations" }\end{array}$ & 6 & 10 \\
\hline $\begin{array}{l}\text { "gestão documental } \\
\text { nas organizações" }\end{array}$ & 0 & 0 & $\begin{array}{l}\text { "document } \\
\text { management in } \\
\text { organizations" }\end{array}$ & 0 & 1 \\
\hline |-------------------- & --------- & --------- & $\begin{array}{l}\text { "record management } \\
\text { in organizations" }\end{array}$ & 0 & 4 \\
\hline Total & 0 & 6 & & 3.934 & 532 \\
\hline
\end{tabular}

Fonte: Elaborada pelos autores.

A tabela 3 expõe o título dos trabalhos recuperados e a formação acadêmica atual e anterior dos autores dessas pesquisas, a fim de verificar o interesse dos profissionais da Administração na Ciência da Informação e vice-versa, como uma maneira de especializar seus conhecimentos administrativos.

Tabela 3 - Análise da Formação Acadêmica e Profissional dos autores das pesquisas interdisciplinares entre Ciência da Informação e Administração

\begin{tabular}{|c|c|c|c|c|}
\hline $\begin{array}{l}\text { Título das } \\
\text { pesquisas }\end{array}$ & $\begin{array}{l}\text { Área do } \\
\text { Periódico }\end{array}$ & Autores & $\begin{array}{l}\text { Formação atual dos } \\
\text { autores }\end{array}$ & $\begin{array}{l}\text { Formação anterior } \\
\text { dos autores }\end{array}$ \\
\hline $\begin{array}{c}\text { A informação como } \\
\text { elemento de } \\
\text { integração entre } \\
\text { propósito, } \\
\text { processos e } \\
\text { pessoas em } \\
\text { instituições } \\
\text { brasileiras e } \\
\text { portuguesas }\end{array}$ & Administração & $\begin{array}{l}{ }^{1} \text { Andrade, } \\
\text { Antônio } \\
\text { Rodrigues; } \\
{ }^{2} \text { Roseira, } \\
\text { Catarina }\end{array}$ & $\begin{array}{l}{ }^{1} \text { Pós-doutor em Ciência } \\
\text { da Informação } \\
{ }^{2} \text { O lattes não retornou } \\
\text { nenhum resultado }\end{array}$ & $\begin{array}{l}\text { 1Pós-Doutor em } \\
\text { Administração; } \\
\text { Mestre em Ciência da } \\
\text { Informação; } \\
\text { Especialista em } \\
\text { Sistemas de } \\
\text { Informação e } \\
\text { Graduado em } \\
\text { Administração. } \\
{ }^{2} \text { O lattes não } \\
\text { retornou nenhum } \\
\text { resultado }\end{array}$ \\
\hline
\end{tabular}




\begin{tabular}{|c|c|c|c|c|}
\hline $\begin{array}{c}\text { A relação entre a } \\
\text { Ciência da } \\
\text { Informação e a } \\
\text { Ciência da } \\
\text { Administração }\end{array}$ & $\begin{array}{l}\text { Ciência da } \\
\text { Informação }\end{array}$ & $\begin{array}{c}{ }^{1} \text { Alves, Claudio } \\
\text { Augusto; } \\
\text { 2Duarte, } \\
\text { Emeide } \\
\text { Nobrega }\end{array}$ & $\begin{array}{l}{ }^{1} \text { Mestre em Ciência da } \\
\text { Informação. } \\
{ }^{2} \text { Pós-doutora em } \\
\text { Ciência da Informação }\end{array}$ & $\begin{array}{l}{ }^{1} \text { Especialista em } \\
\text { Gestão Pública e } \\
\text { Graduado em } \\
\text { Administração. } \\
\text { ²Doutora em } \\
\text { Administração; } \\
\text { Mestre em } \\
\text { Biblioteconomia; } \\
\text { Especialista em } \\
\text { Documentação } \\
\text { Científica; Especialista } \\
\text { em Administração de } \\
\text { Arquivos e Graduada } \\
\text { em Biblioteconomia. }\end{array}$ \\
\hline $\begin{array}{c}\text { Análise } \\
\text { bibliométrica dos } \\
\text { temas inteligência } \\
\text { competitiva, gestão } \\
\text { do conhecimento e } \\
\text { conhecimento } \\
\text { organizacional, no } \\
\text { repositório } \\
\text { institucional da } \\
\text { universidade de } \\
\text { Brasília }\end{array}$ & $\begin{array}{l}\text { Ciência da } \\
\text { Informação }\end{array}$ & $\begin{array}{l}{ }^{1} \text { Araújo Júnior, } \\
\text { Rogério } \\
\text { Henrique de; } \\
\text { 2Perucchi, } \\
\text { Valmira; }{ }^{3} \text { Lopes, } \\
\text { Paulo Roberto } \\
\text { Danelon }\end{array}$ & $\begin{array}{l}\text { 1Doutor em Ciências da } \\
\text { Informação. } \\
\text { 2Doutora em Ciência da } \\
\text { Informação. } \\
\text { 3Doutor em Ciências } \\
\text { da Informação. }\end{array}$ & $\begin{array}{l}{ }^{1} \text { Mestre em Ciências } \\
\text { da Informação e } \\
\text { Graduado em } \\
\text { Biblioteconomia e } \\
\text { Documentação. } \\
{ }^{2} \text { Mestre em Ciência } \\
\text { da Informação; } \\
\text { Especialista em } \\
\text { Educação Ambiental; } \\
\text { Especialista em } \\
\text { Fundamentos } \\
\text { Psicopedagógicos do } \\
\text { Ensino e Graduada } \\
\text { em Biblioteconomia. } \\
\text { 3Mestre em Ciências } \\
\text { Militares; Especialista } \\
\text { em Logística e } \\
\text { Mobilização Nacional; } \\
\text { Especialização em } \\
\text { Psicopedagogia; } \\
\text { Graduado em } \\
\text { Administração de } \\
\text { Empresas e Graduado } \\
\text { em Comunicações. }\end{array}$ \\
\hline $\begin{array}{l}\text { Análise das } \\
\text { relações } \\
\text { interdisciplinares } \\
\text { das pesquisas } \\
\text { científicas em } \\
\text { sistemas de } \\
\text { informação }\end{array}$ & $\begin{array}{l}\text { Ciência da } \\
\text { Informação }\end{array}$ & $\begin{array}{l}\text { Dias, Fernando } \\
\text { Skackauskas }\end{array}$ & $\begin{array}{l}\text { Doutorado em Ciências } \\
\text { da Informação. }\end{array}$ & $\begin{array}{l}\text { Mestre em Ciência da } \\
\text { Informação; } \\
\text { Especialista em } \\
\text { Gestão Estratégica de } \\
\text { Negócios; Especialista } \\
\text { em Análise de } \\
\text { Sistemas e Graduado } \\
\text { em Administração de } \\
\text { Empresas. }\end{array}$ \\
\hline
\end{tabular}




\begin{tabular}{|c|c|c|c|c|}
\hline $\begin{array}{c}\text { Um modelo de } \\
\text { gestão da } \\
\text { informação para } \\
\text { aprendizagem } \\
\text { organizacional em } \\
\text { projetos } \\
\text { empresariais }\end{array}$ & $\begin{array}{l}\text { Ciência da } \\
\text { Informação }\end{array}$ & $\begin{array}{l}{ }^{1} \text { Monteiro, } \\
\text { Nabor Alves; } \\
{ }^{2} \text { Falsarella, } \\
\text { Orandi Mina }\end{array}$ & $\begin{array}{l}{ }^{1} \text { Mestre em Ciência da } \\
\text { Informação. } \\
{ }^{2} \text { Doutor em Engenharia } \\
\text { Mecânica. }\end{array}$ & $\begin{array}{l}{ }^{1} \text { Mestre em } \\
\text { Administração e } \\
\text { Graduado em } \\
\text { Matemática. } \\
{ }^{2} \text { Mestre em } \\
\text { Informática e } \\
\text { Graduado em Análise } \\
\text { de Sistemas. }\end{array}$ \\
\hline
\end{tabular}

Fonte: Elaborada pelos autores.

Como pode ser visto na Tabela 3, praticamente todos os autores das pesquisas recuperadas que envolvem a interdisciplinaridade entre a $\mathrm{Cl}$ e a Administração possuem formação interdisciplinar entre as áreas. Muitos deles possuem graduação em Administração e buscam formação em Ciência da Informação, ou são graduados em áreas relacionadas à Ciência da Informação e buscam formações voltadas à Administração.

Isso demonstra que essas áreas se comunicam e estão em constantes relacionamentos, mesmo porque é possível afirmar que atualmente a união desses campos torna-se muito importante para o avanço das organizações. Afinal, dados, informação e conhecimento se tornaram recursos estratégicos e passíveis de gerenciamento para os ambientes organizacionais.

A Cl necessita da Administração para expandir o reconhecimento da área diante da sociedade, que em grande parte desconhece o seu relevante papel. É óbvio que essa área não está voltada apenas à gestão da informação e à gestão documental nas empresas como foi enfatizado nessa pesquisa. Mas, presume-se que esses processos são essenciais para a inserção da área do meio profissional e no mercado de trabalho.

A Administração depende da Ciência da Informação para especializar seus planejamentos estratégicos, para utilizar metodologias e processos de cuidado e gestão com a informação, documentação e com o conhecimento, que vão potencializar os resultados das empresas. É por esses motivos que se acredita, mediante essa pesquisa, que a Ciência da Informação possui potencialidade para se tornar também uma ciência administrativa.

Segundo Alves e Duarte (2015), o principal ponto de intersecção entre a Ciência da Informação e a Ciência da Administração está no objetivo de compreender o objeto e a aplicação da informação nos contextos organizacionais ou em centros de documentação e informação. Ao mesmo passo, de acordo com os autores, a parceria estabelecida entre essas ciências é realizada de maneira tão sensível e minuciosa que nenhuma das duas perdem sua identidade, muito pelo contrário, fortalecem uma a outra. 


\section{Considerações Finais}

A Ciência da Informação é um campo interdisciplinar que se relaciona com diversas outras áreas do conhecimento, como a biblioteconomia, arquivologia, museologia, ciência da computação, direito, filosofia, administração, entre outras. Esses relacionamentos se dão pelo fato de que todas essas áreas utilizam a informação em seus processos de trabalho.

Este trabalho procurou enfatizar a relação entre a Ciência da Informação e a Administração, que são complementares, especialmente porque o objeto da $\mathrm{Cl}$ é a própria informação, que é considerada recurso estratégico para os contextos organizacionais. A primeira área domina os processos de gestão da informação e gestão documental, que foram colocadas aqui como umas das principais metodologias utilizadas pela Administração, no intuito de potencializar o sucesso das empresas. Além disso, pode-se dizer que a $\mathrm{Cl}$, em alguns casos, utiliza os ambientes organizacionais como universos de pesquisa para sua aplicação.

Ao analisar a formação dos autores, pôde-se concluir que pessoas graduadas em Administração estão propensas a buscarem especialização, principalmente em nível de Stricto Senso, em Ciência da Informação. Neste caso, infere-se que esse campo possui potencialidade para se tornar um tipo de ciência administrativa, todavia, como se torna abusivo generalizar a área toda como uma possível ciência da administração, presume-se que alguns eixos da $\mathrm{Cl}$ buscam apoiar o campo da Administração. Afinal, o contexto societal para isso acontecer existe, pois, informação e conhecimento possuem muito valor, ademais, como o campo da Administração é bem popularizado e consistente mediante a sociedade, o ambiente acadêmico e o mercado de trabalho, acredita-se que essa inter-relação que a $\mathrm{Cl}$ estabelece com a Administração também pode naturalmente contribuir para o reconhecimento e consistência da $\mathrm{Cl}$ perante a sociedade e o mercado de trabalho dos profissionais da informação.

O estudo enfrentou limitações relacionadas ao receio de relacionar os campos da Administração e da Ciência da Informação como complementares, além de inferir que a Ciência da Informação também pode ser considerada futuramente como uma ciência administrativa, no entanto, de certa maneira, essas limitações estimularam o desenvolvimento desta pesquisa, mesmo porque as autoras acreditam na estreita e importante relação entre a Administração e a Ciência da Informação.

Por fim, como sugestão para pesquisas futuras, indica-se uma investigação que tenha como objetivo analisar o perfil curricular dos pesquisadores inseridos em programas de mestrado e doutorado em Ciência da Informação, a fim de verificar se esses possuem formação anterior em administração e áreas afins. Além disso, selecionar uma amostra de 
pesquisadores que possuem essa formação e perguntar o que os motivou a fazer um curso na área da Ciência da Informação.

\section{Agradecimentos}

À Coordenação de Aperfeiçoamento de Pessoal de Nível Superior (CAPES) e ao Conselho Nacional de Desenvolvimento Científico e Tecnológico (CNPq) pelo financiamento e apoio a essa pesquisa.

\section{Referências}

ALVARENGA NETO, R. C. D. Gestão do conhecimento em organizações: proposta de mapeamento conceitual integrativo. São Paulo: Saraiva, 2008.

ALVES, Claudio Augusto.; DUARTE, Emeide Nobrega. A relação entre a Ciência da Informação e a Ciência da Administração. TransInformação, v. 27, n. 1, p.37-46, jan./abr., 2015. Disponível em:

<http://www.scielo.br/scielo.php?pid=S010337862015000100037\&script=sci abstract\&tlng=p t>. Acesso em: 02 abr. 2018.

ARAÚJO, C. A. A. O que é ciência da informação? Informação \& Informação, v. 19, n. 1, p. 1-30, jan./abr., $2014 . \quad$ Disponivel em: $<$ http://www.uel.br/revistas/uel/index.php/informacao/article/view/15958>. Acesso em: 28 mar. 2018.

ARQUIVO NACIONAL (BRASIL). Dicionário brasileiro de terminologia arquivística. Rio de Janeiro: Arquivo Nacional, 2005. 232p.

BARBOSA, R. R.; PAIM, I. Da GRI à gestão do conhecimento. In: PAIM, I. (Org.). A gestão da informação e do conhecimento. Belo Horizonte: Escola de Ciência da Informação da UFMG, 2003.

BARRETO, Aldo de Albuquerque. Uma história da Ciência da Informação. In: TOUTAIN, Lídia Maria Batista Brandão (Org.). Para entender a Ciência da Informação. Salvador: EDUFBA, 2007, p. 13-34.

BEAL, A. Gestão estratégica da informação: como transformar a informação e a tecnologia da informação em fatores de crescimento e alto desempenho das organizações. São Paulo: Atlas, 2008.

BERNARDES, I. P.; DELATORRE, H. Gestão documental aplicada. São Paulo: Arquivo Público do Estado de São Paulo, 2008.

BORKO, Harold. Information Science: what is it? American Documentation, v. 19, n. 1, p. 3-5, 1968.

CALDERON, W. R.; CORNELSEN, J.M.; PAVEZI, N.; LOPES, M.A. O processo de gestão documental e da informação arquivística no ambiente universitário. Ciência da Informação, Brasília, v. 33, n.
3 ,
p.
97-104,
set./dez.
2004.
Disponível
em: 
<http://www.scielo.br/pdf/ci/v33n3/a11v33n3.pdf>. Acesso em: 03 jul. 2018.

CALLON, Michel.; COURTIAL, Jean Pierre.; PENAN, H. Cientometría: la medición de la actividad científica de la bibliometría a la vigilancia tecnológica. España: Trea, 1995.

CAPURRO, Rafael.; HJORLAND, Birger. O conceito de informação. Perspectivas em Ciência da Informação, v. 12, n. 1, p. 148-207, jan./abr. 2007. Disponível em: $<$ http://portaldeperiodicos.eci.ufmg.br/index.php/pci/article/view/54 >. Acesso em: $01 \mathrm{abr}$. 2018.

CHOO, C.W. A organização do conhecimento: como as organizações usam a informação para criar significado, construir conhecimento e tomar decisões. São Paulo: SENAC, 2003. 425p.

CONARQ. E-Arq: modelo de requisitos para sistemas de informatizados de gestão arquivística de documentos: versão 1.1. Rio de Janeiro: Arquivo Nacional, 2011.

DAVENPORT, T .H. Ecologia da informação: por que só a tecnologia não basta para o sucesso na era da informação. São Paulo: Futura, 2001.

DE SORDI, J. O. Administração da informação: fundamentos e práticas para uma nova gestão do conhecimento. São Paulo: Saraiva, 2008.

DURANTI, L. Registros documentais contemporâneos como prova de ação. Estudo Históricos, Rio de Janeiro, v. 7, n. 13, p. 50-57, jan./jun. 1994. Disponível em: <http://bibliotecadigital.fgv.br/ojs/index.php/reh/article/view/1976 >. Acesso em: 04 jul. 2018.

GIL, Antonio Carlos. Como elaborar projetos de pesquisa. São Paulo: Atlas, 2012.

GOFFMAN, W. Information science: discipline or disappearance. ASLIB Proceedings, v. 22, n. 12, p. 589-596, 1970.

HEREDIA HERRERA, A. Archivística general: teoría y práctica. Sevilla, Espanha: Diputación Provincial de Sevilla, 1993.

INDOLFO, A. Gestão de Documentos: uma renovação epistemológica no universo da Arquivologia. Arquivística.net, Rio de Janeiro, v. 3, p. 28-60, 2007. Disponível em: $<$ http://www.brapci.inf.br/v/a/5190 >. Acesso em: 03 jul. 2018.

SANTOS, V. B. dos. A prática arquivística em tempos de gestão do conhecimento. In: SANTOS, V. B. dos. Arquivística: temas contemporâneos: classificação, preservação, gestão do conhecimento. Distrito Federal: SENAC, 2007. cap. 3, p. 175-219.

SANTOS, V. Preservação de documentos arquivísticos digitais. Ciência da Informação, Rio de Janeiro, v. 41, n. 1, p. 114-126, 2012. Disponível em: <http://revista.ibict.br/ciinf/article/viewFile/1357/1536 >. Acesso em: 04 jul. 2018.

SARACEVIC, Tefko. Ciência da Informação: origem, evolução e relações. Perspectivas em Ciência da Informação, v. 1, n. 1, p. 41-62, jan./jun., 1996. Disponível em: $<$ http://portaldeperiodicos.eci.ufmg.br/index.php/pci/article/view/235 >. Acesso em: 02 abr. 2018.

SHERA, J. H.; CLEVELAND, D. B. History and foundations of Information Science. Annual Review 
of Information Science and Technology, v. 12, p. 248-275, 1977 apud BRAGA, Gilda Maria. Informação, ciência da informação: breves reflexões em três tempos. Ciência da Informação, Brasília, v. 1, n. 24, p. 1-8, abr. 1995. Disponível em: $<$ http://revista.ibict.br/ciinf/index.php/ciinf/article/viewFile/534/486 >. Acesso em: 04 abr. 2018.

QUEIROZ, Daniela Gralha de Caneda.; MOURA, Ana Maria Mielniczuk. Ciência da Informação: história, conceitos e características. Em questão, Porto Alegre, v. 21, n. 3, p. 25-42, ago./dez. 2015. Disponível em: <http://seer.ufrgs.br/index.php/EmQuestao/article/view/57516 >. Acesso em: 05 abr. 2018.

PONJUÁN DANTE, G. Gestión de información en las organizaciones: principios, conceptos y aplicaciones. Santiago: CECAPI, 1998. 222 p.

PONJUÁN DANTE, Glória. Gestión de información: dimensiones e implementación para el éxito organizacional. España: Trea, 2007.

RASCÃO, J. P. Da gestão estratégica à gestão estratégica da informação: como aumentar o tempo disponível para a tomada de decisão estratégica. Rio de Janeiro: E-Papers, 2006.

SANTOS, Elinaldo. O campo científico da administração: uma análise a partir do círculo das matrizes teóricas. Cadernos EBAPE.BR, v. 15, n. 2, p. 209-228, abr./jun., 2017. Disponível em: $<$ http://bibliotecadigital.fgv.br/ojs/index.php/cadernosebape/article/view/52841 >. Acesso em: 05 abr. 2018.

TARAPANOFF, K. Referencial teórico: introdução. In: TARAPANOFF, K. (Org.). Inteligência organizacional e competitiva. Brasília: Editora UnB, 2001, 343p.

VALENTIM, M. L. P. Informação e conhecimento em organizações complexas. In: VALENTIM, M. L. P. (Org.). Gestão da Informação e do Conhecimento. São Paulo: Polis: Cultura Acadêmica, 2008. 